\title{
Reuna
}

\section{CENTRALIDADE DO TRABALHO, APOSENTADORIA E SEUS DESDOBRAMENTOS BIOPSICOSSOCIAIS}

\author{
CENTRALITY OF LABOR, RETIREMENT AND ITS BIOPSYCHOSOCIAL \\ DEVELOPMENTS
}

http://dx.doi.org/10.21714/2179-8834/2017v22n1p83-102

\author{
Cíntia Dietrich Hoffmann \\ Centro Universitário Novos Horizontes, Brasil. \\ Endereço: R. Alvarenga Peixoto, 1270 - Santo Agostinho, CEP 30180-121, Belo Horizonte, MG - Brasil. \\ Fone: Tel: +55 31 3349-2900 \\ Email: hoffmann.cintia@gmail.com - Lattes: http://lattes.cnpq.br/4173133995747186

\section{Luciano Pereira Zille} \\ Universidade Federal de Minas Gerais, Brasil. \\ Endereço: Rua Alvarenga Peixoto, 1270 - Santo Agostinho. 30.180-121 - Belo Horizonte - MG. - Brasil \\ Fone: +55 31 3409- 7245 \\ Email: Izille@face.ufmg.br - Lattes: http://lattes.cnpq.br/4239395807663687
}

Submissão: 17 Fev. 2017 Publicação: 31 Mar. 2017. Sistema de avaliação: Double blind review. Centro Universitário UNA, Belo Horizonte - MG, Brasil. Editor geral Prof. Dr. Mário Teixeira Reis Neto

Este artigo encontra-se disponível no endereço eletrônico:

Reuna: http://revistas.una.br/index.php/reuna/article/view/878

DOI: http://dx.doi.org/10.21714/2179-8834/2017v22n1p83-102

\section{Resumo}

O trabalho exerce papel central na vida humana, proporcionando a construção da identidade e dos vínculos sociais. $\mathrm{Na}$ aposentadoria, essa condição deixa de existir e pode desencadear manifestações de ordem orgânica, psicológica e social, com repercussões importantes na estrutura psíquica dos indivíduos. O estudo teve por objetivo identificar e descrever os impactos biopsicossociais vivenciados por aposentados durante esta etapa da vida. Em termos metodológicos, a pesquisa caracterizou-se como descritiva, por meio de estudo de múltiplos casos, com abordagem qualitativa, e os dados foram analisados pela técnica de análise de conteúdo. Os resultados revelaram manifestações de ordem orgânica, como insônia, hipertensão arterial e dores osteomusculares; manifestações de ordem psicológica, com ocorrência de depressão, sentimento de menos valia e síndrome do pânico; e ainda, manifestações de ordem social, evidenciando a redução do convívio social e dificuldade com a administração do tempo em relação aos afazeres cotidianos.

Palavras-Chave: Manifestações biopsicossociais; Aposentados; Trabalho.

\section{Abstract}

Labor plays a central role in human life by making it possible to build identity and social ties. After retirement, this condition ceases to exist and it may trigger REUINA, Belo Horizonte - MG, Brasil, v.22, n.I, p.83-102, Jan. - Mar. 2017- ISSN 2179-8834 
manifestations of an organic, psychological, and social nature, with major repercussions upon the psychic structure of individuals. The study aimed at identifying and describing psychosocial impacts undergone by retired individuals during this phase of life. Methodologically, the research is descriptive, as it studied multiple cases from a qualitative stance and the data were analysed by means of content analysis. Results showed organic manifestations such as sleeplessness, high blood pressure, and psyhological osteomialgia, with the occurrence of depression, feelings of unworthiness and panic syndrome. There were also social manifestations showing the reduction of social relations and difficulty in time management when doing everyday chores.

Key words: Retirement, Psychosocial manifestations, Labor.

\section{Introdução}

O trabalho para o ser humano tem importância central na vida, demandando grande parte do tempo dos indivíduos, cuja dinâmica é uma questão social, que proporciona não somente ganhos materiais, como também espaço na construção da identidade, vínculos afetivos e imaginários (ZANELLI; SILVA; SOARES, 2010).

$\mathrm{Na}$ aposentadoria, o vínculo com o trabalho que durante toda a vida ocupou e organizou o tempo, como um espaço de construção da identidade e dos relacionamentos sociais, é interrompido de forma abrupta. Por outro lado, a aposentadoria também é vista no seu contexto legal, ou seja, como uma obrigação do Estado para auxiliar as pessoas que se encontram com as forças físicas enfraquecidas (SALGADO, 1997). Para as organizações, a aposentadoria é uma das formas de desligamento, gerando rotatividade de mão de obra e consequente perda do capital intelectual. Nesse processo, é fundamental que existam preparações, tanto do ponto de vista daqueles que vão se aposentar, preparando-se para uma nova etapa de vida, como também por parte das organizações, no sentido de preservar os conhecimentos e aplicações que se deram ao longo dos anos (ZANELLI; SILVA; SOARES, 2010).

A aposentadoria não é sinônimo de envelhecimento, no entanto, para a sociedade, em que impera a prática do capitalismo, tem relação com a improdutividade econômica, por defasagem de conhecimentos e, muitas vezes, é associada à velhice. Essa visão, na maioria das vezes, leva a uma discriminação social da condição de aposentado (RODRIGUES et al., 2004).

O processo de envelhecer e a forma de lidar com a aposentadoria é particular a cada indivíduo, ao seu modo de enfrentar perdas e se habituar às novas situações impostas. Os recursos de enfrentamento das situações advindas da aposentadoria distinguem-se para cada sujeito. Há pessoas que lidam de forma a enfrentar e superar os obstáculos encontrados, tornando um momento de aprendizagem e de realizações.

Por outro lado, pode se constituir um dos principais desencadeadores de comprometimentos emocionais e sociais, manifestando-se em comportamentos inesperados, psicopatologias não antes apresentadas e atitudes inesperadas (KIM; 
MOEN, 2008). Dessa forma, o envelhecimento excede a esfera da saúde física, muito embora esta exerça grande influência na vida do sujeito aposentado.

Diante do exposto, como explicar as manifestações psicossociais em profissionais aposentados?

Para nortear o presente estudo, teve-se como objetivo geral identificar e descrever os impactos psicossociais vivenciados na percepção dos aposentados durante esta etapa da vida.

O estudo faz-se oportuno no âmbito social, uma vez que a população idosa é cada vez mais representativa. Contudo, apesar da crescente longevidade e do número de aposentados no Brasil, há pouca preocupação com esta população, sendo latente a necessidade de reconhecimento social e a garantia de condições dignas com a melhoria da qualidade de vida. No contexto acadêmico, busca contribuir e aprofundar os estudos nesse campo, visto que esta temática ainda é incipiente no Brasil (ZANELLI; SILVA; SOARES, 2010; FRANÇA, 2008), além de assistir propostas de intervenção nas esferas organizacionais e sociais.

O estudo ora apresentado está organizado em três seções, além desta introdução. A seguir será apresentado o referencial teórico, em que se aborda aspectos relacionados à aposentadoria, como também os contextos psicossociais envolvidos nessa etapa. A seguir será retratada a metodologia do estudo empírico e, por fim, o relato de cinco casos de aposentados estudados.

\section{Referencial teórico}

Nesta seção, os conteúdos apresentados estão relacionados a questões inerentes à aposentadoria e suas repercussões biopsicossociais, relacionadas aos contextos biológico, psicológico e social.

\subsection{A aposentadoria e as manifestações psicossociais}

A aposentadoria é a "ação de se afastar do trabalho após completar certo tempo de serviço, estipulada pela lei; por ter atingido certa idade, ou por motivo de saúde, é posto em inatividade e passa a receber uma pensão" (MINISTÉRIO DA PREVIDÊNCIA SOCIAL, 2015).

Segundo a Lei $\mathrm{n}^{-}$8.213/1995, a aposentadoria é um direito concedido aos trabalhadores e pode ocorrer de forma integral ou proporcional. Para o trabalhador receber a aposentadoria de forma integral, deverá ter 35 anos de contribuição e 65 anos de idade, no caso de homens, e 30 anos de contribuição e 60 anos de idade para as mulheres. Para requisição do benefício de forma proporcional, o trabalhador deve ter, pelo menos, 30 anos de contribuição e ter atingido a idade de 53 anos, no caso de homens, e 48 anos, mulheres. Há ainda a modalidade de aposentadoria especial (trabalhadores expostos à insalubridade) e também por invalidez, em caso de doença ou acidente, sendo que as duas últimas modalidades não são foco do presente estudo.

Em 04 de novembro de 2015, foi sancionada a Lei 13.183, que é uma alternativa aos outros tipos de aposentadoria. Esta lei cria uma nova fórmula para o cálculo de REUNA, Belo Horizonte - MG, Brasil, v.2Z, n.I, p.83-102, Jan. - Маг. 2017 - ISSN 2179-8034 
aposentadorias. Somando-se a idade do contribuinte com o tempo de contribuição, é possível se aposentar com 85 pontos, no caso das mulheres, e com 95 pontos, para homens. Essa fórmula só poderá ser aplicada se houver um tempo mínimo de contribuição, ou seja, 30 anos para mulheres e 35 para os homens. A lei também prevê um escalonamento progressivo de um ponto a cada dois anos a partir de 2018, até se atingir o resultado de 90 pontos para as mulheres e 100 para os homens, em 2026.

O benefício da aposentadoria, de natureza contributiva, garante um rendimento seguro no futuro e pode ser obtido de três formas distintas: Regime Geral de Previdência Social (RGPS); Regimes Próprios de Previdência dos Servidores Públicos (RPPSP); e Regime Complementar Privado (BATISTA; LUSENI; EI-MOOR, 2008). No RGPS e o RPPSP é obrigatória a adesão a todos que possuem vínculos formais de trabalho, seja na esfera privada (RGPS), seja na esfera pública (RPPSP). Já o Regime Complementar Privado tem caráter complementar e facultativo e, baseado na constituição de reservas, garante o benefício na aposentadoria.

Para o Estatuto do Idoso, lei 10741/2003, enquadram-se na definição de idoso aquelas pessoas com mais de 60 anos, faixa etária próxima à da concessão da aposentadoria.

Para a Organização Mundial de Saúde - OMS (2002), idoso refere-se a uma pessoa com mais de 65 anos de idade, se for residente em países desenvolvidos e, para os países em desenvolvimento, aquelas com mais de 60 anos. Nos últimos anos, vem aumentado o número de idosos em todo o mundo e também no Brasil.

Após a Segunda Guerra Mundial, houve significativa diminuição das taxas de mortalidade nos países desenvolvidos. No Brasil, o envelhecimento populacional vem ocorrendo de forma mais intensa a partir da década de 60 . Redução da mortalidade, diminuição das taxas de fecundidade e desenvolvimento da tecnologia médica são fatores que contribuem para o aumento da expectativa de vida da população (CHAIMOWICZ, 1997; CANÇADO, 1996).

Minayo (2007) acrescenta a esses fatores a redução da pobreza, o maior ingresso nos serviços de saúde, a extensão da cobertura previdenciária, a redução do analfabetismo e ainda o fomento de políticas públicas.

A elevação da expectativa de vida e a redução das taxas de mortalidade fazem com que haja uma previsão de que, até 2060, um quarto da população brasileira será composto por pessoas com mais de 65 anos, sendo 81 milhões de beneficiários da Previdência Social (IBGE, 2010). Dessa forma, a população idosa, depois de se aposentar, ainda tem a expectativa de viver vários anos de forma ativa.

De acordo com o Instituto Brasileiro de Geografia (IBGE, 2011), em 2010, o número de brasileiros com mais de 60 anos era de 23,5 milhões, mais que o dobro do registrado em 1991. A idade cronológica não é precisa quanto às alterações que acometem a terceira idade. Cada pessoa possui particularidades quanto aos aspectos relacionados ao estado de sua saúde, níveis de dependência e ao processo de envelhecimento.

A vivência da aposentadoria pode ser dividida em 5 fases, com atitudes positivas e negativas do sujeito frente a este novo período de vida. A primeira fase é de euforia, experiênciada como liberdade. Depois, sob a realidade cotidiana, o sujeito vivencia uma queda do entusiasmo inicial. Essa mesma realidade faz com o sujeito se 
reoriente e perceba as oportunidades ao seu redor, caracterizando a terceira fase. Em seguida, vem a fase da estabilidade, do equilíbrio. Por fim, a quinta fase evidencia um eventual declínio frente às doenças e debilidades físicas (REITZES, MUTRAN, 2004).

\subsubsection{Manifestações biopsicossociais}

Durante todas as etapas da vida, o ser humano se depara com mudanças de diversas naturezas, sendo necessário se adaptar a elas. Com a aposentadoria e a chegada da terceira idade não é diferente. Esse momento é permeado por questões delicadas, multidimensionais e interligadas entre si. Desenvolvimento e declínio, numa relação dialética entre ganhos e perdas, permeiam essa etapa, muito embora as perdas sejam as mais expressivas (BALTES, 1997). Emanam transformações biológicas, sociais e psicológicas que acometem de forma particular cada sujeito, as quais serão tratadas a seguir.

É importante salientar que é fundamental analisar a aposentadoria sob diversos prismas, no entanto eles não são estanques. Um exerce influência sobre o outro numa relação universal, uma vez que o sujeito é uno.

\subsubsection{Manifestações orgânicas}

Do ponto de vista orgânico, o envelhecimento traz consigo algumas debilidades físicas. Dores osteomusculares são comuns, bem como o surgimento de diabetes, dispneias (muitas vezes desencadeadas por infartos e pneumonias), disúria, disfunção erétil, derrame, degeneração macular e demência (CHARNESS, 1987).

No final da década de 90, Chaimowicz (1997) realizou estudo com a população idosa das cidades de Belo Horizonte, São Paulo e Rio de Janeiro a fim de analisar as condições de saúde desse grupo de indivíduos. Os resultados constataram que é elevado o índice de patologias crônicas, como osteoartrite e dispneia. Em outra pesquisa, realizada com a população da cidade de São Paulo, constatou-se que $90 \%$ dos idosos tinham pelo menos uma doença crônica não-transmissível (RAMOS, 2003). Apesar de o envelhecimento não estar ligado a doenças e a incapacidades, é na população idosa que as doenças crônico-degenerativas prevalentemente se manifestam.

Em 2008, as doenças que mais prevaleciam na população idosa eram a hipertensão arterial (53\%), dor na coluna ou nas costas (35\%), reumatismo (24\%), doenças coronarianas (17\%), diabetes (16\%), além de outras doenças (20\%) (IBGE, 2008).

A aposentadoria é um dos principais responsáveis por suscitar comprometimentos funcionais, no entanto, muitas vezes esse fator torna-se despercebido (CANIZARES; JACOB FILHO, 2011). Estudos indicam que tabagismo, sedentarismo, obesidade e estresse presentes na pré-aposentadoria tendem a se acentuar comprometendo a saúde dos aposentados (PIENTA, HAYWARD, 2002).

Outra manifestação que pode ser suscitada é a insônia, manifestando-se como dificuldade inicial para dormir, redução das horas de sono ou ainda o não alcance dos estágios do sono reparador (CORRÊA; CEOLIM, 2008).

\subsubsection{Manifestações psíquicas}

RELUNA, Belo Horizonte - MG, Brasil, v.2Z, n.l, p.83-102, Jan. - Мar. ZDI7 - ISSN 2179-8834 
O trabalho é uma das principais vias de saída das pulsões e, segundo Freud (1997), um dos melhores caminhos para se encontrar a felicidade. Dessa forma, o trabalho desempenha um importante papel na vida do homem, relacionando-se à sua dinâmica psíquica e consolidação de sua identidade. O espaço ocupado pelo trabalho na existência humana é um regulador da organização da vida, do tempo e do espaço, permitindo realizações e bem-estar, seja pelo mecanismo da sublimação ou pela inserção no grupo social (FREUD,1997). É comum trabalhadores assumirem como sobrenome o nome da empresa ou o cargo que ocupam, sendo o trabalho uma referência para o sujeito. Dessa forma, há uma particular relação não só com o trabalho em si, mas também com o grupo de convívio (ZANELLI; SILVA; SOARES, 2010).

Nos grupos de convívio no trabalho, é desejável que sejam estabelecidos mecanismos para que cada um de seus participantes se identifique com o grupo, de modo que possam ser reconhecidos como profissionais e como pessoas. A identidade de cada um é firmada quando corroborada por outras pessoas que configuram objetivos similares. Criam-se vínculos, desenvolvem-se afetos. Vão sendo moldados hábitos e costumes peculiares ao grupo, que se diferencia e se torna único. Quanto mais estreitas as relações e maior a satisfação pelo convívio com o grupo, somadas aos laços como trabalho em si e projetos que se tenha, mais dificuldade pode-se ter no rompimento. "É o que se vê acontecer tanto no desemprego quanto na aposentadoria" (ZANELLI; SILVA; SOARES, 2010, p.37).

A aposentadoria é um momento de transição para uma nova etapa na vida, que marca o desenvolvimento humano. $O$ indivíduo precisa ressignificar sua vida, sua colocação social e sua identidade. “... o homem, como criatura psicossocial, defrontar-se-á (...) com uma nova edição da crise de identidade” (ERIKSON, 1987, p. 141).

Com a aposentadoria, há perda do vínculo com o trabalho, a qual, inicialmente, pode ser acompanhada de uma sensação de liberdade e euforia. Com o passar do tempo, a ociosidade pode dar lugar a um sentimento de inutilidade, improdutividade, solidão, dentre outros, desencadeando um desequilíbrio emocional e social (REITZES; MUTRAN, 2004). Fatores de risco podem advir nessa etapa, como sedentarismo, inadequados hábitos alimentares e dependência química (RAMOS, 2003; PIMENTA et al., 2008).

Muitas pessoas almejam, fazem planos para a aposentadoria e vislumbram essa etapa como tempo de liberdade. Outras associam este momento como um processo de perda, comprometendo seu bem-estar (BULLA; KAEFER, 2003).

Outra questão de cunho psicológico e que acomete grande parte da população idosa é a depressão (CHARNESS, 1987; MANN, 1991; PIMENTA et al., 2008; GAMEIRO et al., 2014;), apresentando-se como um risco à integridade cognitiva (ALVARENGA et al., 2009). Segundo Gameiro et al. (2014), frequentemente o estresse é gatilho para desencadear a depressão em idosos, que se apresenta de forma complexa e é associada, sobretudo, a aspectos psicossociais, como solidão, aposentadoria, perda de emprego e aspectos não tratados durante a vida.

Também pode-se elencar o estresse como uma das consequências da aposentadoria. Pesquisas apontam que, além da aposentadoria, os principais fatores desencadeadores do estresse se relacionam com a finitude (morte ou 
doença) e ainda problemas que afetam os descendentes (ADLWIN; SUTTON; LACHMAN, 1996; FORTES-BURGOS; NERI; CUPERTINO, 2009).

Se antes o trabalho preenchia grande parte do tempo do sujeito, agora ele se vê com o tempo livre para organizá-lo conforme sua vontade. Com isso, pode-se desencadear o estresse de monotonia, situação em que a estrutura psíquica do sujeito se encontra pouco estimulada pelas demandas psíquicas do meio, ao contrário do estresse de sobrecarga, decorrente de excessivas demandas psíquicas do ambiente. Assim, no estresse de monotonia, a estrutura psíquica do indivíduo comporta muito mais pressão do que o ambiente lhe proporciona (SELYE, 1974; COUTO, 1987).

A ocupação do tempo livre com atividades prazerosas passa a ser um dos principais motivos de preocupação dos aposentados (ZANELLI; SILVA; SOARES, 2010). Nesse sentido, as condições de vida e o modo como encara essa nova fase da vida podem contribuir para a saúde ou para o desenvolvimento do estresse, além de outras patologias.

É comum que na aposentadoria haja mudança no padrão de vida do aposentado. A depressão, o estresse e outras manifestações são resultado, muitas vezes, do despreparo emocional dos trabalhadores para lidar com esse novo marco da trajetória profissional e consequentemente do desenvolvimento humano (CINTRA; RIBEIRO; ANDRADE, 2010).

\subsubsection{Manifestações sociais}

Além das questões orgânicas e psicológicas, soma-se as questões de cunho social. Há mudança do referencial de vida, ou seja, o aposentado passa da condição de trabalhador para ex-trabalhador, de ativo para inativo, de contribuinte da previdência social para beneficiário.

Essa identidade é um marco na vida do indivíduo que decreta a velhice, mesmo que, biologicamente, não se enquadre nessa fase (SALGADO, 1997). Santos (1990, p.2) também colabora com esta visão, considerando que:

no modo de produção da sociedade na qual existimos, que, em geral, supervaloriza a produção e aliena o trabalhador do processo produtivo, a aposentadoria é geralmente experienciada como a perda da vida, configurada como uma espécie de morte social. Ao se valorizar apenas aqueles que produzem do ponto de vista racional e econômico, deprecia-se o ser humano aposentado.

Muitas vezes, de forma velada e inconsciente, a sociedade considera a aposentadoria como sinônimo de velhice, de decadência da vida, de proximidade de sua finitude, de peso social e de período cercado de muitos adoecimentos (VIEIRA, 1999; ZANELLI; SILVA; SOARES, 2010). As pessoas nessa condição podem sofrer com a discriminação, preconceito e também com o isolamento social e familiar, em que o sentimento vivenciado é de improdutividade e de inatividade.

Enquanto trabalhador, inserido no contexto organizacional, o sujeito cria vínculos afetivos e sociais. Muitas empresas promovem confraternizações e momentos de integração entre seus funcionários. Esses momentos passam a inexistir ou ficam empobrecidos na aposentadoria. O sujeito se vê com seu círculo de amizades reduzido. Além da perda do status profissional, há perda do status social. Uma 
relação importante com o aspecto biológico que se pode fazer é de que, quanto mais o indivíduo estiver envolto em círculos sociais, praticar atividades físicas e ser constantemente estimulado intelectualmente, menores serão as suas chances de caminhar em direção à demência (RAMOS, 2003).

Ainda no contexto social, pode haver dificuldades financeiras, trazendo preocupação ao aposentado. Apesar dos casos de rendimento vitalício, esse valor pecuniário, na maioria das vezes, é menor do que recebia enquanto trabalhava. Ainda ocorre perda dos benefícios, denominada remuneração indireta, como vale-alimentação, refeição, comissões, plano de saúde, cesta básica, entre outros. A maioria desses benefícios são utilizados de forma discricionária pela organização, não são incorporados ao salário e, por sua vez, não são considerados para os cálculos previdenciários. Soma-se a essa questão o aumento de gastos, sobretudo com a saúde (NERI, 2007).

Além dos aspectos financeiros, estudos apontam que os idosos se preocupam com problemas familiares, sobretudo dos filhos e netos, os quais trazem uma reflexão sobre o papel do próprio sujeito enquanto educador, denunciando falhas nessa direção. O idoso não tem controle sobre esse evento, o que poderá contribuir para o estabelecimento ou agravamento do estresse (FORTES-BURGOS; NERI; CUPERTINO, 2009).

Alguns fatores sociais e econômicos são fundamentais para o enfrentamento sadio da aposentadoria, tais como o nível de escolaridade, condições de moradia, idade, recebimento de benefícios previdenciários ou de proteção social, rendas alternativas, contato com parentes e amigos, dentre outros (FURTADO, 2005).

Diante da extensão da expectativa de vida, é imperativo um olhar para os aposentados. O indivíduo, bem como sua família e organização, precisa estar preparado para este momento, fazendo com que o aposentado não fique à margem da sociedade, constituindo-se, portanto, um tempo de novas realizações.

\section{Metodologia}

O presente estudo trata-se de uma pesquisa descritiva, que expõe características de um determinado fenômeno, por meio da precisão dos detalhes, no caso específico, as manifestações psicossociais de cunho biológico, psicológico e social vivenciadas por sujeitos aposentados.

Em relação ao método, utilizou-se o estudo de múltiplos casos, que, de acordo com Yin (2005), está relacionado às narrativas identificadas nos casos estudados. A abordagem foi de natureza qualitativa, em que se procurou compreender 0 fenômeno estudado, segundo a percepção dos indivíduos. Nessa direção,"o raciocínio se baseia principalmente na percepção e na compreensão humana" (STAKE, 2011, p. 21).

A unidade de análise consistiu no processo de aposentadoria e suas intercorrências com as manifestações psicossociais, por meio de cinco sujeitos aposentados com mais com mais de 65 anos de idade, de ambos os sexos, que se encontravam na condição de aposentados, há pelo menos um ano, possuindo autonomia para as demandas da própria vida. Domiciliados na região metropolitana da cidade de Belo 
Horizonte/MG e, no momento da pesquisa, não possuíam vínculo empregatício formal.

O Sindicato dos Aposentados e Pensionistas do Estado de Minas Gerais (SINAP) indicou sujeitos que poderiam participar da pesquisa dentre os critérios estabelecidos. Aleatoriamente, identificaram-se dez sujeitos dessa relação, dos quais cinco se propuseram e concordaram em participar do estudo. Dessa forma, os entrevistados foram selecionados de acordo com o critério de acessibilidade.

A coleta dos dados foi realizada por meio de entrevistas individuais semiestruturadas. Foram coletados dados de natureza demográfica e funcional, como idade, sexo, tempo de aposentadoria, profissão e função exercida quando da ativa. Dados sobre a rotina diária dos sujeitos, além de questões relacionadas aos contextos físico, psicológico e social, de forma a atender aos objetivos do estudo. Os entrevistados foram contatados previamente, ocasião em que foram agendados os encontros presenciais, realizados na própria residência dos entrevistados. $\mathrm{Na}$ ocasião da entrevista, explicitaram-se os objetivos da pesquisa, bem como as condições de sigilo da identidade que seriam mantidas. Cada entrevista foi realizada num único encontro, com duração média de 40 minutos.

Para a análise dos dados, estes foram organizados em categorias de análise ou categorias temáticas, segundo a técnica de análise de conteúdo, conforme preconiza Bardin (2006), caracterizada como "um conjunto de técnicas de análise das comunicações", com objetivo de interpretá-las (BARDIN, 2006, p.33). As categorias analisadas foram: aposentadoria, manifestações biológicas, manifestações psíquicas e manifestações sociais.

\section{Apresentação e discussão dos casos}

Nesta seção serão apresentados os casos estudados e discutidos os respectivos resultados. O caso um é um sujeito do sexo masculino de 77 anos, casado, com ensino médio completo, o qual exercia a função de supervisor de motorista, aposentado há 21 anos. O caso 2 trata-se de sujeito do sexo feminino, com 77 anos de idade, viúva, com escolaridade equivalente ao ensino médio completo, exercia a função de serviços gerais e está aposentada há 20 anos. O sujeito do caso 3 tem 67 anos, também é do sexo feminino, casada, possui ensino superior completo, bancária e faz 7 anos que se aposentou. $O$ caso 4 refere-se a um sujeito do sexo masculino, com 68 anos de idade, casado, com escolaridade equivalente ao ensino médio. Trabalhou como policial militar e encontra-se há 18 anos na condição de aposentado. Finalmente o caso 5 , que é o de um sujeito do sexo feminino, com 66 anos, casada, possui ensino superior completo, bancária, estando há um ano na condição de aposentada.

Em relação aos dados demográficos e funcionais, predominaram os sujeitos do sexo feminino (3); a idade variou entre 66 e 77 anos; e a escolaridade predominante foi o ensino médio completo (3) e 2 sujeitos com curso superior, também completo. As funções exercidas pelos participantes foram motorista, serviços gerais, policial militar e 2 sujeitos exerceram a função de bancário. O tempo de aposentadoria variou de 1 a 22 anos, com média de 13 anos. 
A seguir, será apresentado, de forma individualizada, cada um dos cinco casos estudados anteriormente enunciados.

\section{Caso 1}

O sujeito deste caso, ora referenciado como P1, é do sexo masculino, tem 77 anos, casado, possui ensino médio completo. Aposentou-se há 21 anos e a última função exercida foi de supervisor de motoristas em uma empresa de transportes coletivos urbanos, ficando seis anos nesta função de supervisão. A aposentadoria ocorreu às "pressas", pois na época veiculava-se a notícia de que um determinado benefício inerente à função exercida iria se extinguir quando da aposentadoria. Com receio, aposentou-se faltando oito meses para completar os 35 anos de trabalho. A complementação do tempo de aposentadoria é um requisito importante a ser considerado no processo de aposentadoria para preservar os ganhos decorrentes, em patamar superior.

Após se aposentar, iniciou outra atividade relacionada à venda de cosméticos de porta em porta. Isso lhe garante, até hoje, uma renda extra e os benefícios aferidos com a atividade lhe proporcionam a complementação dos ganhos relativos à aposentadoria, conforme comenta o sujeito:

[...] e não posso parar mais. Se eu parar de vender esse negócio, eu não sei mais o que vou fazer. Ficar em casa vendo televisão? Não tem jeito. Arrumar um emprego? Fora de cogitação. [...] Se amanhã ou depois falar assim, ah... não, vou vender isso mais não, eu vou sentir falta. Esse negócio até me ajudou muito. Tenho quase certeza que não vou conseguir parar mais, fiz tanta amizade com o pessoal [...] $\mathrm{E}$, além disso, às vezes a gente conversa sobre a vida. Então a gente tá acompanhando as coisas (P1).

O trabalho formal, aquele com registro na carteira de trabalho, não se tornou uma realidade para o sujeito, então $\mathrm{P1}$ buscou uma fonte alternativa de renda, que foi a venda de cosméticos. Além dos ganhos financeiros decorrentes dessa atividade, esta proporciona o preenchimento do tempo, pois o trabalho ocupa o espaço vazio trazido pela aposentadoria. Relata ainda que essa atividade é importante para o seu relacionamento e interação com as pessoas, garantindo seu espaço social.

Os ganhos da aposentadoria percebidos são a independência, flexibilidade de horários e liberdade para fazer as atividades no tempo e no modo desejado, o que antes da aposentadoria não era possível, pois se sentia como um "passarinho na gaiola (P1)".

P1 não se queixa em relação às condições financeiras. Além do benefício da aposentadoria recebido, complementa a renda com as atividades informais que realiza, conforme relatado. Aponta ainda que esse adicional depende dele e que, se quiser ganhar mais, basta trabalhar mais. Logo após a aposentadoria, pensou em procurar um trabalho formal, no entanto a contrapartida salarial não foi considerada como satisfatória, por isso procurou por rendas alternativas.

Com relação aos aspectos orgânicos, apresenta manifestação de diabetes e hipertensão arterial, as quais se encontram controladas pelas atividades físicas que realiza de forma regular, como também pelo acompanhamento médico. Relata que, em alguns dias acorda indisposto e cansado. 
Do ponto de vista psicológico, P1 procura encarar as situações com bom humor e tranquilidade, sempre com pensamentos positivos. Os relatos a seguir ilustram essas situações:

Não fico muito quieto assim não... não consigo ficar quieto sem olhar ao redor. Eu gosto de participar, interagir com as pessoas. Eu gosto de mostrar que tô vivo, que tô participando da sociedade, da vida das pessoas. [...] acho que nem posso parar mais. Se amanhã ou depois falar assim, ah... não vou vender isso mais não... eu vou sentir falta. Esse negócio até me ajudou muito. Tenho quase certeza que não vou conseguir parar mais...

Percebe-se que $\mathrm{P} 1$ ressignificou o seu tempo com um trabalho que lhe proporciona muito mais do que renda, traz-lhe uma sensação de utilidade, de pertencimento e participação na sociedade. Para ele essa questão é tão importante que, muitas vezes, abre mão de seus finais de semana e feriados para vender. O trabalho continua a exercer um papel central na vida de P1, que julga esses momentos como prazerosos, sem os quais a vida perderia o sentido.

Nota-se que, mesmo apresentando algumas questões orgânicas, diabetes e hipertensão arterial, P1 está equilibrado emocional e socialmente, enquadrando-se na terceira fase da aposentadoria postulada por Reitzes e Mutran (2004), que é a fase da estabilidade.

\title{
Caso 2
}

A segunda participante deste estudo, P2, é do sexo feminino, tem 77 anos de idade, viúva, possui ensino médio completo e exercia a função de serviços gerais em uma empresa prestadora de serviços na cidade de Belo Horizonte. Faz 20 anos que se aposentou. Atualmente mora sozinha e realiza todas as suas atividades de forma independente e, embora se sinta bem e capaz, sua família não a vê dessa forma. Identifica claramente uma distinção da tratativa enquanto trabalhava de forma vinculada e estava ativa economicamente, para o momento atual, na condição de aposentada.

\begin{abstract}
Não posso fazer as coisas. Meu filho vem pra cá e fica me falando o que tenho que fazer. [...] Quando eu trabalhava não tinha essa amolação [da família]. Eles acham que não consigo fazer as coisas sozinha, que não posso morar sozinha, que não consigo fazer nada. Quando eu trabalhava podia fazer tudo, ajudava a pagar as contas, fazia tudo sozinha. Agora, ah... não é a mesma coisa.
\end{abstract}

Desde quando se casou, estabeleceu uma rotina de acordar cedo, fazer o café e arrumar os filhos para irem à escola, para em seguida ir trabalhar. Quando chegou a aposentadoria, os filhos já não estavam mais em casa, o marido faleceu pouco tempo depois e P2 se viu sozinha. Dessa forma, passou a preencher o tempo com "muitas obrigações". Diz-se muito ocupada e envolta em muitas atividades, no entanto, não soube precisar com exatidão quais são essas tarefas, mas impera o desejo de continuar se sentindo útil e reconhecida pelas atividades que desempenha, uma vez que a sociedade é pautada pelo valor produtivo, e sua família legitima essa questão. Se não puder continuar exercendo seus afazeres, mesmo que imaginários, é o decreto da morte. 
O que fico mais chateada é minha depressão. Me sinto triste, infeliz. Fico pensando quando vai ser minha hora... meu marido já foi. Fico falando com Deus: se é para ficar numa cadeira de rodas, prefiro que me leve logo. Converso muito com ele [com Deus] e falo assim mesmo pra ele: ficar dependendo dos outros não quero não, sempre fiz minhas coisas e agora não quero mesmo que os outros venham aqui e façam minhas coisas. [...] Eu peço muito a Deus pra me livrar disso e das coisas que fico pensando.

Há aproximadamente cinco anos foi diagnosticada com depressão, que é uma das doenças que mais acomete os idosos (CHARNESS, 1987). Contribuindo com essa questão, a morte, assunto evitado porque lembra a finitude da condição humana, faz-se muito presente no dia a dia de P2. Relata que vários de seus amigos, familiares e vizinhos já faleceram.

A religiosidade é muito presente na vida de $\mathrm{P} 2$, recorrendo a Deus como o único que poderá livrá-la das difíceis situações suportadas. Estudos constatam que a religiosidade na maturidade e velhice contribui para o enfrentamento dessas dificuldades, como também o estresse, além do enfrentamento de outras questões que acometem os idosos, sendo esta uma questão muito relevante em relação às situações vivenciadas no caso relatado (GOLDSTEIN; NERI, 1993).

Verificou-se também que P2 apresenta fragilidades, principalmente, de cunho psicológico. As debilidades, reais ou impostas pela família, apresentam desafios adaptativos. A depressão desencadeada pelo sentimento de finitude, impotência e menos valia é um dos principais componentes atuais em sua vida. A depressão gera reflexos sociais, uma vez que, em virtude disso, abstém-se do convívio social. Observam-se também manifestações de cunho orgânico, gerando sintomas físicos, como emagrecimento e alteração frequente do sono.

\section{Caso 3}

A terceira participante, P3, tem 67 anos, é do sexo feminino, casada, possui ensino superior completo e faz sete anos que se aposentou. Durante toda sua vida profissional atuou como bancária.

Depois de trabalhar por mais de 25 anos em uma determinada instituição financeira exercendo o cargo de gerente de agência, ela se aposentou, levando em consideração os incentivos da instituição. Depois de aposentada, viu-se com necessidade de preencher o tempo livre e iniciou os estudos para concurso público. Foi aprovada em concurso e nomeada em outra instituição financeira como escriturária. Lá trabalhou por cerca de 1 mês e pediu para ser desligada porque não se adaptou às atividades do cargo.

Estudos demonstram que, quanto maior o nível de escolaridade e de renda, maiores serão as condições de o sujeito enfrentar a aposentadoria de forma saudável (ALGARÍN; BERNAL; SANCHEZ-SERRANO, 2007).

Hoje, P3 se diz tranquila, pois as atividades do banco eram muito estressantes e o deslocamento no trânsito para chegar ao trabalho também gerava níveis importantes de tensão. Atualmente vem ocupando o seu tempo com as atividades de casa e com o envolvimento na igreja e em trabalhos sociais, como visita a asilos e outros 
correlatos. Além disso, pratica atividades físicas de forma regular. O relato a seguir ilustra essa situação.

Procuro me engajar no serviço da igreja. Nós temos um pequeno grupo e fazemos visita a um asilo de idosos uma vez por mês. [...] Uma coisa que eu vejo que é muito importante é estar ligada a um grupo religioso, de ter as atividades ali regulares, ter as leituras, principalmente as leituras bíblicas. É muito importante sim.

Um comparativo que estabelece entre o tempo em que trabalhava e o atual é a administração do tempo. Os horários para o cumprimento do trabalho, de certa forma, ajudavam na organização e otimização do tempo. A P3 relata que agora procrastina muito e acaba "desperdiçando" tempo pela falta de um limitador.

Financeiramente, a aposentadoria suscita um desequilíbrio econômico para uma parcela da sociedade (NERI, 2007). No caso de P3, não houve perdas significativas nessa direção, como pode ser observado no relato a seguir:

\footnotetext{
É, assim, o meu caso particular é diferente de outras pessoas, muita gente que se vê, nas conversas e em entrevistas, a questão da renda do aposentado pelo INSS apenas, a perda de rendimentos é muito grande. Já no meu caso, que tenho a complementação do fundo de pensão, isso já não tem seu peso, mesmo tendo caído um pouco, mas não é alarmante, não me preocupa.
}

Do ponto de vista social, relata que houve redução no círculo de amizades e nas atividades sociais, embora afirme que não precise do outro e que consiga ficar sozinha.

Do ponto de vista orgânico, sente muitas dores musculares e insônia. O aumento da idade coincide com a aposentadoria e, muitas vezes, com o surgimento de doenças. P3 considera suas dores como processo natural do envelhecimento.

Depois da aposentadoria, considera que a preocupação com os familiares se exacerbou. Expõe um medo, sobretudo da violência e do trânsito. Durante a fase infanto-juvenil dos filhos, não houve auxílio do pai das crianças ou de outra pessoa, e P3 se manteve ausente do convívio de casa para trabalhar. Além do apego afetivo presente, esse medo presente na atual vida de P3 pode denunciar dificuldades no processo de educação conduzido pelos pais, o que pode levar a manifestações de estresse (FORTES-BURGOS; NERI; CUPERTINO, 2009).

Identificam-se também questões de cunho social, prevalecentes na vida de P3, como a regulação do tempo, antes realizada pelo trabalho, e o preenchimento do tempo com a realização de trabalhos voluntários.

\section{Caso 4}

O sujeito 4 é do sexo masculino, tem 68 anos de idade, casado, possui ensino médio, em termos de escolaridade. Trabalhou como policial militar e encontra-se há 18 anos na condição de aposentado.

Quando na ativa, P4 era responsável por um grande contingente de policiais e muitas atribuições na corporação. Relata que era "pura correria" e trabalhava inclusive aos finais de semana e, por inúmeras vezes, mesmo em suas folgas, o convocavam para resolver alguns problemas relacionados ao trabalho. Nesse REUNA, Belo Horizonte - MG, Brasil, v.2Z, n.I, p.83-102, Jan. - Маг. 2017 - ISSN 2179-8034 
cenário, vislumbrava a aposentadoria como sendo um momento para "relaxar, curtir a vida", visitar os amigos e fazer muitas viagens.

Aos 51 anos se aposentou e o cenário vivenciado foi bem diferente do almejado. Logo no início, desenvolveu quadro de insônia e precisou recorrer a medicamentos para dormir. Ao se deitar, ficava preocupado, imaginava o barulho de sirenes e a possibilidade de poder ser chamado a qualquer momento para uma ocorrência policial. Aos poucos, a insônia foi dando lugar à síndrome do pânico. Após um ano de aposentado, foi diagnosticado com a síndrome, mas à época não fez tratamento algum, tendo o quadro agravado. Até hoje relata que tem síndrome do pânico, o que o impede de ficar em locais fechados. Hoje, faz acompanhamento com psiquiatra e toma medicamentos para controlar os sintomas provocados pela síndrome.

O sonho das viagens não foi concretizado, pois um de seus maiores pânicos é entrar em avião. Por diversas vezes, chegou a comprar passagem, mas não embarcou, ou, em um certo momento, teve que descer do avião.

\begin{abstract}
Tenho isso [síndrome do pânico] sempre que preciso viajar de avião. A mulher adora viajar e queria viajar para todos os lados. Ela tem filhos fora e sempre viaja. Quando ela fala que quer ir já até me dá um ataque cardíaco. E ela me "enche o saco". Falo que vou pensar e depois desisto, daí ela perde as promoções do avião. Teve uma vez que fiquei com pânico no trem. Acho que o problema é lugar que me deixa trancado, não gosto. Ah, já teve vezes no ônibus também.
\end{abstract}

Relata ainda que, quando trabalhava, não tinha tempo para pensar em mais nada. Sua rotina era em torno, unicamente, das atividades da polícia. A aposentadoria pode ter se dado como fuga do trabalho considerado estressante, mas, uma vez aposentado, podem advir dificuldades de satisfação, de sentir-se útil, de ocupar o tempo com outros afazeres, além de sentimentos de solidão. Não fez preparação para a aposentadoria e não buscou nenhuma atividade que pudesse preencher esse tempo, apenas idealizava este momento libertador.

Era acostumado a lidar com muitas demandas, pressões e constantes perigos inerentes ao cargo que ocupava, e agora se vê tendo que cuidar, exclusivamente, da própria vida. O corpo e a mente eram demandados a todo tempo. A aposentadoria vislumbrada como um alívio não teve a correlação com a realidade e veio cercada de frustrações. A rotina de trabalho foi interrompida abruptamente para se libertar dos constantes eventos estressantes vivenciados no trabalho. Todavia o aposentado agora se vê sem ter o que fazer. O estudo de Pienta e Hayward (2002) aponta que na aposentadoria os níveis de estresse de monotonia podem emergir em função da ruptura abrupta da rotina de trabalho, nessa nova situação, bastante desacelerada e sem a devida preparação.

Em relação à síndrome do pânico e à aposentadoria, mesmo não se obtendo correlato na literatura, pode ser entendida, no caso estudado, principalmente em função da proximidade temporal dos fatos ocorridos, como função de experiências mal sucedidas em relação às vivências experienciadas.

Relata também outros problemas de saúde, como úlcera estomacal e perda auditiva, mas os justifica como sendo normais no processo do envelhecimento. "A gente vai ficando velho e vão aparecendo essas coisas. É igual carro, precisa de mexer!" (P4).

Expõe ainda que não possui dificuldades financeiras, pois há outras fontes de renda, como aluguéis de imóveis de sua propriedade. 
A centralidade neste caso reside nas questões psicológicas, mais precisamente em relação à síndrome do pânico, desencadeada após a aposentadoria. As questões orgânicas manifestadas, como úlcera e insônia, podem ter relação com o estresse vivenciado nos últimos tempos ou com a síndrome do pânico relatada.

$\mathrm{P} 4$, num primeiro momento, vivenciou a aposentadoria com muita euforia, mas não houve uma elaboração do luto pela perda do trabalho e, mesmo depois de 18 anos de aposentado, não conseguiu se reorientar nem buscar alternativas para dar sentido ao seu tempo.

\section{Caso 5}

A quinta participante, P5, é do sexo feminino, possui 66 anos, é casada e tem ensino superior completo. Exerceu a função de bancária e faz um ano que se encontra na condição de aposentada.

Relata que apresentou certa dificuldade inicial para se adaptar à condição de aposentada, o que pode ser ilustrado pela fala a seguir:

Logo no início, demorei a me acostumar com a ideia de que estava aposentada. Eu não queria muito me aposentar, já tinha idade pra isso, mas pensava em como seria sem o meu trabalho. Meu primeiro emprego foi no banco. Tudo o que eu sei aprendi lá, todas as minhas coisas, minha casa, meu carro, minhas viagens, os estudos dos meus filhos paguei com o dinheiro que ganhava no banco. Então você sente uma consideração (P5).

Observa-se não só uma centralidade do trabalho, mas também um sentimento de gratidão. $O$ relato a seguir ilustra esta situação:

Em casa ficava andando de um lado para o outro. Daí pensei comigo: quero ficar assim por quanto tempo? Me sentia muito bem trabalhando e quero continuar a me sentir bem... então tenho que dar novos sentidos, não é mesmo?! Acho que se não fizer nada, fico muito estressada mesmo... tenho que buscar alguma coisa. Nesse tempo teve umas 4 vezes que acordei, me arrumei e fui trabalhar. No meio do caminho via que não precisa mais (P5).

O desequilíbrio trazido pela perda da identidade e do vínculo com o trabalho é uma circunstância que exige do sujeito mecanismos de adaptação. A participante, mesmo aposentada, demonstra manter uma rotina diária de afazeres, que contribui para sua autoestima. P5 fez um movimento de ressignificar seu tempo, com novas ocupações, cuidando da casa, dos netos, das plantas, aprender nova língua, programar e realizar viagens e leituras. Esse movimento afirma um sentimento de utilidade e fortalece as relações nos seus diversos ambientes, conforme relato a seguir: "É bom também se sentir útil, produtiva. Ainda me sinto capaz. Poderia estar trabalhando tranquilamente ainda hoje. Não aposentei por causa de doença nem nada, entende?!" (P5).

No entanto, embora tenha aumentado os relacionamentos familiares, houve redução no círculo de amizades, em relação aos grupos externos à família, sendo excluída de festas e outras confraternizações.

Do ponto de vista orgânico, a participante manifesta insônia; socialmente, redução do convívio social; e, psicologicamente, o vazio trazido pela perda do vínculo com o 
trabalho, que gerou um movimento de ressignificação do tempo e dos afazeres em geral.

\section{Considerações finais}

O presente estudo teve como objetivo central identificar e descrever os impactos psicossociais vivenciados na percepção dos aposentados durante esta etapa da vida.

O trabalho possui uma centralidade na vida do ser humano, e o rompimento desse vínculo pode desencadear manifestações de várias ordens (ZANELLI; SILVA; SOARES, 2010). $\mathrm{Na}$ aposentadoria o sujeito pode vislumbrar como momento de ganhos e de crescimento pessoal, mas também pode vivenciá-lo como um período de perdas e de eventos estressantes.

Para se alcançar o objetivo proposto, realizou-se pesquisa descritiva, de abordagem qualitativa, por meio de estudo de multicasos, com cinco sujeitos que concordaram em participar da pesquisa. Cada um dos cinco casos apresentados traz elementos inerentes à condição de aposentado, apresentando também elementos particulares a cada sujeito, caracterizando a heterogeneidade do envelhecimento. A cessação do trabalho e do contexto laborativo tem impacto nas circunstâncias da vida da pessoa, mesmo que cada um vivencie esta etapa de maneira particular.

Em termos de resultados, os participantes demonstraram manifestações orgânicas, psicológicas e sociais, muito embora, em cada caso, prevaleçam determinadas particularidades em função das diferenças individuais. Analisando separadamente cada caso, observaram-se as seguintes situações:

Em relação ao $\mathrm{P} 1$, o trabalho ainda hoje é um ponto central na sua vida. Apresenta manifestações orgânicas com destaque para o diabetes e hipertensão arterial. P2 manifesta sintomas de depressão, que na sua percepção apresenta causa multifatorial. Já a participante 3 se queixa da procrastinação em virtude da falta da organização do tempo trazida pelo trabalho. O participante 4 desenvolveu insônia e síndrome do pânico logo após se aposentar. E, por fim, P5 mostra um forte sentimento de gratidão à única empresa em que trabalhou. Esse sentimento, inicialmente, trouxe um vazio, o qual foi preenchido com outras atividades no âmbito de seu contexto de vida.

A aposentadoria se apresenta como uma fase de perdas e ganhos. Ao mesmo tempo em que os entrevistados relataram a aposentadoria como algo merecido e um período para aproveitar o tempo livre, retomando projetos e interesses, por outro lado, identificaram-se fontes de tensão em decorrência deste novo período de vida, sobretudo pela perda da identidade trazida pelas mudanças decorrentes do contexto de trabalho.

Relatos apontaram para as dificuldades no processo de aposentadoria e também na ocupação do tempo livre. O preenchimento do tempo é um dos principais motivos de REUUNA, Belo Horizonte - MG, Brasil, v.22, n.I, p.83-102, Jan. - Mar. 2017 - ISSN 2179-8834 
apreensão. Na aposentadoria, o sujeito passa de uma fase regulada pelo trabalho para uma em que a administração do tempo livre faz-se fundamental no planejamento de vida de cada indivíduo. Assim, o planejamento e a reorganização do tempo, contemplando novas atividades, sejam de trabalho ou de lazer, possibilitam um enfrentamento mais positivo dessa nova etapa na vida dos sujeitos.

Além de dificuldades em relação à adaptação inicial, também foram apontadas outras fontes de tensão, como sentimento de improdutividade, falta de autonomia, dificuldades em relação ao gerenciamento do tempo e redução do círculo de amizades e convívio social. Dessa forma, pode-se perceber o trabalho como organizador da rotina e dos horários, além de estabelecer planos, possibilitar realizações e laços afetivos.

A aposentadoria é um luto, havendo a necessidade de elaboração e construção de novos sentidos para a vida. A maioria dos aposentados pesquisados conseguiu fazer esta travessia de forma saudável, e várias estratégias defensivas foram apontadas em decorrência das mudanças vivenciadas, sendo a principal delas a ocupação com outras atividades e reinserção em novos grupos sociais.

É prescrita, no Estatuto do Idoso, a garantia do bem-estar e das condições de saúde do idoso, no entanto, ações com esta população ainda são incipientes no Brasil. Dessa forma, o presente estudo tem a intenção de contribuir para o subsídio de ações de preparação para a aposentadoria e também aquelas de promoção ao envelhecimento bem-sucedido, além de poder cooperar com outras pesquisas em relação ao tema pesquisado.

Mesmo com a centralidade do trabalho, não se reduz todos os problemas enfrentados em decorrência da aposentadoria. É inegável que tem um papel fundamental nesse processo e a sua condução, principalmente, no suporte social e familiar e em programas de preparação para esta etapa da vida, o que poderia minimizar os efeitos deletérios para os indivíduos. A aposentadoria coincide com a entrada na terceira idade, e questões de cunho orgânico, psíquico e social tendem a emergir. No entanto, deve-se buscar entender o histórico do sujeito e todas as outras dimensões da sua vida, com vistas a ações proativas em prol da saúde, que mais do que à ausência de doenças, está relacionada ao bem-estar físico, psíquico e social.

Nessa direção, sugere-se a continuidade dos estudos, buscando o seu aprofundamento, levando-se em consideração algumas variáveis como gênero, idade, preparação para a aposentadoria, família, doenças possivelmente relacionadas, estresse de monotonia, bem como outras que poderiam ser de interesse da pesquisa.

\section{Referências}

ALDWIN, C. M.; SUTTON, K. J.; LANCHMAN, M. The development of coping resources in adulthood. Journal of Personality, v. 64, p. 837-871, 1996.

ALGARÍN, E. B.; BERNAL, J. L. M; SANCHÉZ-SERRANO, J. L. S. Evolución de la preparación a la jubilación em la empresa. Aposta: Revista de Ciencias Sociales, n. 35, out.-dez., 2007. 
ALVARENGA, L. N., KIYAN, L.; BITENCOURT, B. and W.; SILVA, K. NUBIA, L. Repercussões da aposentadoria na qualidade de vida do idoso. Revista Enfermagem USP, v. 43, n. 4, p. 796-802, 2009.

BALTES, P. B. Theoretical propositions of life-span developmental psychology: on the dinamics between growth and decline. Developmental Psychology, v. 5, p. 611626, 1997.

BARDIN, L. Análise de conteúdo. Lisboa: Edições 70, 2006. $281 \mathrm{p}$.

BATISTA, A. S.; LUSENI, L. B. J.; El-MOOR, P. D. Envelhecimento e dependência: desafios para a organização da proteção social. Coleção Previdência Social. v. 28, Brasília: MPS, SPPS, 2008.

BRASIL, Lei no 1074/2003. Estatuto do idoso, Diário Oficial da União, Brasília: DF, 2003.

BRASIL, Lei no 13183/2015. Diário Oficial da União, Brasília: DF, 2015.

BRASIL, Lei no 8213/1995. Dispõe sobre os planos de benefícios da Previdência Social e dá outras providências. Diário Oficial da União, Brasília: DF, 1995.

BULLA, L.; KAEFER, C. Trabalho e aposentadoria. As repercussões sociais na vida do idoso aposentado. Revista Virtual Textos \& Contextos, n. 2, ano II, dez. 2003.

CANÇADO, F. A. X. Epidemiologia do envelhecimento. In: Noções práticas de geriatria. São Paulo: COOPMED, p. 16-43, 1996.

CANIZARES, J. C. L.; JACOB FILHO, W. Fatores de risco à senilidade na transição à aposentadoria. Revista Brasileira de Geriatria e Gerontologia, v. 14, n. 3, p. 425432, 2011.

CHAIMOWICZ, F. A saúde dos idosos brasileiros às vésperas do século XXI: problemas, projeções e alternativas. Revista de Saúde Pública, v. 31, n. 2, p. 184200, 1997.

CHARNESS, N. Aging and human performance. Wiley series on studies in human performance. Waterloo: Wiley, 1987, 392p.

CINTRA, T. S.; RIBEIRO, D. F.; ANDRADE, A. S. O cotidiano de Aposentados que continuam trabalhando de maneira informal na indústria calçadista: percepções sobre a aposentadoria e o trabalho atual. Cadernos de Psicologia Social do Trabalho, v. 13, n. 2, p. 277-287, 2010.

CORRÊA, K.; CEOLIM, M. F. Qualidade do sono em pacientes idosos com patologias vasculares periféricas. Rev Esc Enferm USP. n. 42, p. 12-18, 2008.

COUTO, H. A. Stress e qualidade de vida dos executivos. Rio de Janeiro: COP, 1987, 189p.

ERIKSON, E. H. Identidade, juventude e crise. Trad. Álvaro Cabral. Rio de Janeiro: Guanabara, 1987.

FORTES-BURGOS, A. C. G.; NERI, A. L.; CUPERTINO, A. P. F. B. Eventos estressantes, estratégias de enfrentamento, autoeficácia e sintomas depressivos entre idosos residentes na comunidade. Revista Psicologia: Reflexão e Crítica, v. 14, n. 1, p. 74-82, jan.-abr. 2009.

FRANÇA, L. H. O desafio da aposentadoria. Rio de Janeiro: Rocco, 2008. 
FREUD, S. O mal-estar na civilização. Rio de Janeiro: Imago, 1997.

FURTADO, A. A participação do idoso no mercado de trabalho brasileiro. Consultoria Legislativa. Estudo. Câmara dos Deputados. Brasília, 2005.

GAMEIRO, G. R; MINGUINI, I. P.; ALVES, T. C. L. F. The role of stress and life events in the onset of depression in the elderly. Rev. Médica, p. 31-40, jan.-mar. 2014.

GOLDSTEIN, L. L. L.; NERI, A. L. Tudo bem, graças a Deus! Religiosidade e satisfação na maturidade e na velhice. Rev. Gerontologia, v. 3, n. 1, p. 95-104, 1993.

INSTITUTO BRASILEIRO DE GEOGRAFIA E ESTATÍSTICAS (IBGE). Sinopse do censo demográfico 2010. Rio de Janeiro, 2011.

INSTITUTO BRASILEIRO DE GEOGRAFIA E ESTATÍSTICAS (IBGE). Síntese dos indicadores sociais. Rio de Janeiro, 2008.

INSTITUTO BRASILEIRO DE GEOGRAFIA E ESTATÍSTICAS (IBGE). Síntese dos indicadores sociais: uma análise das condições de vida da população brasileira. Rio de Janeiro, 2010.

KIM, J.; MOEN, P. Retirement transitions, Gender, and Psychological Well-Being: a life-Course, ecological model. Journal Gerontol: psychological Science, n. 57, 2008, p. 212-222.

MANN, J. Retirement: What's happen to husband wife relationships? Journal of Geriatric Psychiatry, v. 24, n. 1, p. 41-46, 1991.

MINAYO, M. C. S. Visão antropológica do envelhecimento. In: Vários colaboradores (orgs). Velhice: reflexões contemporâneas. São Paulo: SESC/PUC. 2007, p. 47-60.

MINISTÉRIO DA PREVIDÊNCIA SOCIAL. Portal Brasil. Disponível em <http://www.brasil.gov.br/economia-e-emprego/2014/05/confira-os-tipos-deaposentadoria-existentes-no-brasil>. Acesso em 29 jun. 2015.

NERI, M. C. Renda, consumo e aposentadoria: evidências, atitudes e percepções. Fundação Getúlio Vargas. Escola de Pós-Graduação em Economia. Ensaios Econômicos. São Paulo, 2007.

ORGANIZAÇÃO MUNDIAL DE SAÚDE, Global Burden of Disease Review. Genebra: Organização Mundial da Saúde, 2002.

PIENTA, A., HAYWARD, M. Who expects to continue working after age 62? The retirement plans of couples. Journal of Gerontology, v. 57B, n. 4, p. 199-208, 2002.

PIMENTA, F. A. P., SIMIL, F. F., TORRES, H. O. G., AMARAL, C. F. S., REZENDE, C. F., COELHO, T. O., REZENDE, N. A. Avaliação da qualidade de vida de aposentados com a utilização do questionário SF-36. Revista da Associação Médica Brasileira, v. 54, p. 55-60, 2008.

RAMOS, L. R. Fatores determinantes do envelhecimento saudável em idosos residentes em centro urbano: Projeto Epidoso, São Paulo. Caderno Saúde Pública, Rio de Janeiro, v. 19, n. 3, p. 793-797, jun. 2003.

REITZES, D. C.; MUTRAN, E. J. The transition to retirement: stages and factors that influence retirement adjustment. Journal Aging and Human Development, v. 59, n. 1, p. 63-84, 2004. 
RODRIGUES, M.; AYABE, N. N.; LUNARDELLI, M. C. F. CANÊO, L. C. A preparação para a aposentadoria: o papel do psicólogo frente a essa questão. Rev. Bras. de Orientação Profissional, n. 24, p. 14-23, 2004.

SALGADO, M. A. A aposentadoria e ética social. Série Terceira Idade. São Paulo: Sesc, p. 4-15, 1997.

SANTOS, M. F. Identidade e aposentadoria. São Paulo: EPU, 1990.

SELYE, H. Stress without distress. Filadélfia, 1974.

STAKE, R. E. Pesquisa qualitativa: estudando como as coisas funcionam. Tradução: Karla Reis. Porto Alegre: Penso, 2011, 263p.

VIEIRA, E. B. A velhice dos tempos atuais. São Paulo: Revista de Psicologia Catharsis, v. 25, p. 17-18, 1999.

YIN, R. K. Estudo de caso: planejamento e métodos. 3. ed. Porto Alegre: Bookman, 2005.

ZANELLI, J. C.; SILVA, N.; SOARES, D. H. P. Orientação para aposentadoria nas organizações de trabalho-construção de projetos para o pós-carreira. Porto Alegre: Artmed, 2010. 